\title{
Genetic diversity and selection within natural dura oil palm accessions collected in Ghana for oil palm productivity improvement
}

\author{
DICKSON OSEI DARKWAH ${ }^{1, \bullet}$, ESSIE BLAY ${ }^{2}$, HARRY AMOATEY ${ }^{3}$, ENOCH SAPEY $^{1}$, \\ CLAUDE BAKOUMÉ ${ }^{4}$, DANIEL AGYEI-DWARKO ${ }^{1}$ \\ ${ }^{1}$ Oil Palm Research Institute. P.O. Box 74, Kusi-Kade, Ghana. Tel. +23-324-8556687, 4611325, +86-130-41293087, ^email: oseidarkwah@yahoo.com \\ ${ }^{2}$ Department of Crop Science, University of Ghana. P.O. Box LG 25, Legon, Accra, Ghana \\ ${ }^{3}$ Ghana Atomic Energy Commission. P.O. Box LG 80, Legon, Accra, Ghana \\ ${ }^{4}$ Maxi Productivity Sarl. P.O. Box 2137, Douala, Cameroon
}

Manuscript received: 22 May 2020. Revision accepted: 10 July 2020

\begin{abstract}
Darkwah DO, Blay E, Amoatey H, Sapey E, Bakoume C, Agyei-Dwarko D. 2020. Genetic diversity and selection within natural dura oil palm accessions collected in Ghana for oil palm productivity improvement. Biodiversitas 21: 3534-3538. The genetic base of oil palm breeding stock of the Ghanaian Oil Palm Research Institute is considered narrow after two selection cycles. Therefore, 79 accessions of natural dura oil palm collected in Ghana and conserved at Oil Palm Research Institute (OPRI) were field evaluated for 18 agro-morphological traits. ANOVA revealed differences among the 79 dura oil palm accessions for 14 traits. The most heritable traits were single fruit weight $\left(h^{2}=0.85\right)$, leaf area index $\left(h^{2}=0.63\right)$, bunch weight $\left(h^{2}=0.52\right)$, total leaf area $\left(h^{2}=0.51\right)$, and fresh fruit bunch $\left(h^{2}=0.46\right)$. Genetic coefficients of variation ranged from $3.30 \%$ for frond dry weight to $68.74 \%$ for total bunch weight denoting possibility of selection of desirable traits for improvement. Five high fresh fruit bunch yielding accessions (FFB $\geq 10.81 \mathrm{t} /$ ha) with good heritable bunch characteristics were selected for introduction in the breeding stocks. In fact, their bunch number, average bunch weight, and mesocarp to fruit were higher, in absolute terms, than the controls and trial mean obtained in the study. Although, the height increment was close to those of the controls, short progenies are expected among descendants from their selfings or crosses.
\end{abstract}

Keywords: Average bunch weight, fresh fruit bunch, genetic coefficient of variation, heritability, natural oil palm

\section{INTRODUCTION}

The oil palm (Elaeis guineensis Jacq.) is a diploid, tropical perennial monocotyledonous species indigenous to Africa. It has $2 \mathrm{n}=2 \mathrm{x}=36$ chromosomes. It is naturally cross-pollinated but is not self-incompatible. On the basis of the shell (Sh) thickness, three types of oil palm are distinguished. Notably (i) dura with a thick shell $(2-8 \mathrm{~mm})$ and homozygous for the trait $\left(\mathrm{Sh}^{+} \mathrm{Sh}^{+}\right)$, (ii) pisifera shellless and homozygous $\left(\mathrm{Sh}^{-} \mathrm{Sh}^{-}\right)$, and (iii) tenera a hybrid from the cross between the dura and pisifera $\left(\mathrm{Sh}^{+} \mathrm{Sh}^{-}\right)$ characterized by a thin shell $(0.5-2 \mathrm{~mm})$. Following the discovery of the genetic inheritance of shell thickness character (Beirnaert and Vanderweijen 1941) since the early1960s, tenera was adopted worldwide as planting material (Bakoumé et al. 2017). Oil palm is cultivated for its oils including palm oil contained in the mesocarp and palm kernel oil contained in the kernel. Palm oil and palm kernel oil have food and non-food uses. Increase in human population and diverse uses of the crop led to a high demand for palm oil that could not be satisfied by natural groves (Bakoumé et al. 2016).

Oil palm selection and breeding work commenced early in the last century in most major oil palm research centers of the world's humid tropics including OPRI in Ghana. The aims of oil palm breeding in Africa are to maximize palm oil (and kernel) yield, to reduce vertical growth to extend the plant's economic life, to select for tolerance to drought to enable expansion of the planting area, to explore new sources of tolerance to Fusarium wilt, and most recently to improve palm oil quality notably high iodine value and low free fatty acids content (Bakoumé et al. 2016). Unfortunately, breeding programs relied on restricted genetic base populations (Ataga et al. 2012) and resulted in slow genetic progress from one cycle of selection to the next, which was the case of Ghana. Varieties of commercial lines produced from such narrow genetic base will be highly similar genetically. In fact, planting materials are tenera (D x P) i.e., hybrids derived from a cross between dura (D) female parents and a pisifera $(\mathrm{P})$ pollen donors. Pisifera is female sterile, the flowers abort after fertilization. Dura is generally Deli dura derived from only four palms introduced in 1848 in the Bongor Botanic Gardens in Java, Indonesia. Dura is known to transmit tolerance to diseases, vertical growth rate, bunch production, and all cytoplasmic-controlled genes to the tenera (hybrid) progenies (Bakoume and Louise 2007). The narrow genetic base of Ghanaian dura breeding stocks has resulted in difficulty of selection for desirable traits. Therefore, there was a need to re-vitalize OPRI's breeding programs by enlarging and enriching the genetic bases of its dura breeding stocks to guarantee substantial genetic advance through selection. Okyere Boateng et al (2008) indicated that oil palm landraces possessing adaptation to local environments are gradually being displaced through (i) felling of palm trees for traditional palm wine production, locally distilled into alcohol, (ii) introduction of improved types, (iii) settlement on new lands due to 
population growth, and (iv) changes in cultivation methods thus accelerating the erosion of these genetic resources in Ghana.

Germplasm constitutes a source of genetic diversity on which further crop improvement programs depend. Adequate evaluation of genetic variability of agronomic and morphological traits within OPRI's natural dura accessions is of paramount importance for the selection of elite accessions to be introduced in the advanced dura stocks. Pratap et al (2012) and Bhandari et al (2017) rightly indicated that genetic variability and genetic relationship among accessions are pivotal to any breeding program and may ameliorate the breeding efficiency with resultant improvement in crop varieties. Assessment of genetic variability for yield, agronomic, and oil quality traits in the natural oil palm accessions collected from Nigeria led to the selection of population 12 by the Malaysian Palm Oil Board (Li-Hammeda et al. 2016). A similar study allowed Okoye et al (2016) to select natural oil palm germplasm accessions to introduce in the Nigeria Institute For Oil Palm Research's (NIFOR) breeding program.

The objective of this study was to evaluate genetic diversity within 79 dura accessions collected from natural oil palm groves of seven regions of Ghana and to select candidate individuals based on their agronomic performances for introduction into OPRI breeding program.

\section{MATERIALS AND METHODS}

\section{Planting materials}

An oil palm germplasm prospection mission was carried out by the OPRI in 2003 to collect natural dura oil palms in seven regions of Ghana for evaluation and utilization of the potential elite accessions for crop improvement and conservation for future use. Seventy-nine accessions were collected from 27 locations using the Descriptors of oil Palm (IPGRI,1989) from open-pollinated oil palms. Open-pollinated bunches were harvested from a standing oil palm reported by inhabitants of the locality. Details of the collected accessions can be found in the attached supplementary sheet. The 79 dura oil palm accessions were laid out in augmented design with two dura standard cross as checks on each block. The checks were Deli dura-derived genitors from OPRI seed production program including 621D descendants of 851:215D self and 48D of 851: 255D x 851:215D cross. Nine accessions each were planted in the first seven blocks and eight accessions in the last two blocks. Six palms were planted per accession. Data were collected per palm and variance estimated for each accession. The experiment was conducted at OPRI, Kusi (0.6.00 N, 001.45W). The soil was Kokofu series also known as Ferri-Plinthic Acrisol by (FAO/ UNESCO Soil Classification). The annual rainfall ranged from 1500 to $2200 \mathrm{~mm}$. The average minimum temperature is $24^{\circ} \mathrm{C}$ and a maximum $34^{\circ} \mathrm{C}$.

\section{Parameters measured}

Vegetative parameters and yield components were recorded for five years (2013 to 2017) and bunch and fruit characters for two years (2016 to 2018). The vegetative parameters viz leaf area (LA), total leaf area (TLA), leaf area index (LAI), frond dry weight (FDW), total fronds (TF), rachis length (RL), plant height $(\mathrm{PH})$, radius of average spread (Ras), and average spread (A/S) were computed using standard procedures described by Sapey et al. (2017). Yield parameters included bunch number (BN), total bunch weight (TBW), and average bunch weight $(\mathrm{ABW})$. Fresh Fruit Bunch (FFB) was estimated according to the formula hereafter:

\section{$\mathrm{FFB}=\mathrm{BN} \times \mathrm{ABW} \times \mathrm{SPH} \times 0.001$}

Where: SPH is stands per hectare (or planting density) and 0.001 a conversion factor of kilogram into tonne.

Bunch and fruit characters viz single fruit weight (SFW), percentage fruit to bunch (F/B), percentage mesocarp to fruit $(\mathrm{M} / \mathrm{F})$, percentage shell to fruit $(\mathrm{S} / \mathrm{F})$, and percentage kernel to fruit $(\mathrm{K} / \mathrm{F})$ were computed following the procedure adopted from (Sapey et al. 2017).

\section{Statistical analysis}

An analysis of variance (ANOVA) was performed for all the vegetative, bunch production, bunch, and fruit parameters measured using R statistical software (R Core Team 2018). Heritabilities $\left(h^{2}\right)$, genetic coefficient of variation (GCV), phenotypic coefficient of variation (PCV), and genetic advance (GA) were computed following the standard procedure described by Farshadfar and Estehghari (2014) considering $10 \%$ selection intensity. Heritability was estimated as

$$
\begin{aligned}
& \mathrm{h}^{2}=\frac{\sigma^{2} \mathrm{~g}}{\sigma^{2} \mathrm{p}} 100 \\
& \mathrm{GCV}=\left(\sqrt{ } \sigma^{2} \mathrm{~g} / \mathrm{x}\right) * 100 \\
& \mathrm{PCV}=\left(\sqrt{ } \sigma^{2} \mathrm{p} / \mathrm{x}\right) * 100 \text { and } \mathrm{GA}=\frac{\mathrm{i}^{*} \sqrt{ } \sigma^{2} \mathrm{p} * \mathrm{~h}^{2}}{\mathrm{~m}} \times 100
\end{aligned}
$$

Where: $\sigma^{2} \mathrm{~g}=$ genotypic variance, $\sigma^{2} \mathrm{p}=$ phenotypic variance, $\mathrm{x}=$ mean, $\mathrm{h}^{2}=$ heritability and $\mathrm{m}$ is the mean of unselected population (population/ grand mean) and $\mathrm{i}=$ selection differential or intensity.

\section{RESULTS AND DISCUSSION}

The ANOVA revealed significant differences between the 79 dura oil palm accessions for 14 traits out of the 18 agronomic traits (Table 1). The variability for the 14 polymorphic traits was useful for the assessment of the genetic diversity that exists among the 79 natural dura accessions. The other four agronomic traits were considered monomorphic and did not contribute to distinguishing one accession from the other. They included $\mathrm{ABW}, \mathrm{F} / \mathrm{B}, \mathrm{K} / \mathrm{F}$, and $\mathrm{TF}$.

The evaluation and characterization of natural dura oil palm in our study aimed to provide knowledge about the extent of genetic variability among accessions (Table 2). 
The study believed in Murugesan et al (2015)'s work in the sense that the improvement of OPRI's dura breeding stocks and high genetic gain in the tenera hybrids would result from the genetic diversity existing within 79 natural dura accessions tested.

Mean plant height values $(25.58-115.03 \mathrm{~cm})$ were close to those reported by Murugesan et al (2015) while the range of rachis length (2.38-4.06 m) was narrow compared to the $1.39-6.92 \mathrm{~m}$. Mean values of TBW (7.01 t/ha/yr) and $\mathrm{BN}$ (6.70) were lower than the $13.51 \mathrm{t} / \mathrm{ha} / \mathrm{yr}$ and 13.5 recorded from 17-year-old oil palm germplasm collected in Cameroon and planted in Malaysia (Bakoume 2016). Nevertheless, mean values of ABW were comparable (7.01 $\mathrm{kg}$ vs $6.9 \mathrm{~kg}$ ). The use of accessions from different regions and assessment of accessions in different environments as well as different ages of oil palm germplasm at the time of the measurements might have accounted for the differences observed.

Wonkyi-Appiah (1987) reported that the yield of mature (14 years old and above) oil palm (local/wild/unimproved) in Ghana was $5.5 \mathrm{t} / \mathrm{ha} / \mathrm{yr}$. In this study, the grand mean was $7.01 \mathrm{t} / \mathrm{ha} / \mathrm{yr}$, with $77 \%$ of the accessions yielding above the $5.5 \mathrm{t} / \mathrm{ha} / \mathrm{yr}$. Furthermore, FFB yields of $60 \%$ of the accessions were above the trial mean of $7.01 \mathrm{t} / \mathrm{ha} / \mathrm{yr}$. The highest yielder was the accession GHA 212/02 whose annual TBW (14.33 t/ha/yr) represented $104 \%$ of the trial mean indicated the possibility to select accessions for FFB improvement of current OPRI's dura breeding stocks in Ghana.

Broad sense heritability estimates for the 14 polymorphic agro-morphological traits ranged from $1.73 \%$ for $\mathrm{F} / \mathrm{S}$ to $85.27 \%$ for SFW (Table 2). The ABW, F/B, and TF exhibited zero heritability due to the fact that they did not reveal differences between accessions in the ANOVA. The result was a strong indication that accessions would have derived from the same genetic pool since these traits normally have high heritabilities. Okoye et al. (2009) noted that heritability estimates above $50 \%$ are considered to be high. Single fruit weight $\left(h^{2}=0.85\right)$, leaf area $\left(h^{2}=0.67\right)$, leaf area index $\left(h^{2}=0.63\right)$, total leaf area $\left(h^{2}=0.59\right)$, radius of average spread $\left(h^{2}=0.76\right)$, total bunch weight $\left(h^{2}=0.52\right)$ recorded high heritabilities signifying high possibility of getting them expressed in subsequent generations of OPRI's dura materials. In fact, heritability estimates of 0.67 for leaf area, 0.16 for plant height, 0.46 for fresh fruit bunch, and 0.30 for bunch numbers obtained from this study were within the range reported by earlier workers (Corley and Tinker 2015). However, the heritability for bunch weight obtained in the current study $\left(h^{2}=0.52\right)$ was above the range $(0.12-0.37)$ reported by (Corley and Tinker 2015 ) while 0.26 and 0.02 obtained for percent mesocarp to fruit and kernel to fruit, respectively, were below those reported in previous studies (Corley and Tinker 2015). Differences in genotypes used, number of individuals per accession, environments, and conditions under which the different evaluations were carried may account for differences between heritability estimates reported.

There are no agronomic traits found not to be heritable at all like it was the case in this work for TF, ABW, and F/B. However, previous selection of candidate accessions for introduction in the base populations of OPRI's breeding programs did not place much emphasis on heritability (Okyere Boateng et al 2008).

Genotypic coefficients of variation (GCV) ranged from $3.30 \%$ for frond dry weight to $68.74 \%$ for total bunch weight while the phenotypic coefficients of variation (PCV) ranged from $7.74 \%$ for leaf area index to $98.51 \%$ for plant height. Sayan et al (2013) stated that GCV and PCV values below $10 \%$ were low, between $10 \%$ and $20 \%$ were moderate while those above $20 \%$ were considered high. Generally, moderate to high GCV and PCV values were found in this study. High GCV indicates sufficient variation is available for improvement through selection. In general, PCV was higher than GCV for all traits indicating the important role of the environment on the expression of these traits (Okoye 2008). Narrow differences were observed between PCV and GCV for leaf area, leaf area index, radius of average spread, single fruit weight, and percent mesocarp to fruit. Narrow difference implied higher genetic influence over environmental influence. Narrow difference between GCV and PCV suggests a comparable resistance to environmental influences (Okoye et al 2009).

Genetic advance (GA) indicates the measure of gain attained in a trait considering a particular selection intensity. It also tells of the feasible advancement that will be made in a new population in comparison with the original population after selection. GA values were low to moderate (0.00-12.72\%) for all the 18 agro-morphological traits. According to Ajayi et al (2014), GA values below 10 $\%$ are low, moderate between $10 \%$ and $20 \%$, and considered high above $20 \%$. All the traits except leaf area index, radius of average spread, bunch weight, and fresh fruit bunch recorded low genetic advance while the aforementioned traits had moderate genetic advance. In comparison, Constantin et al (2017) reported higher values for fresh fruit bunch and bunch numbers $24 \%$ and $163 \%$ over those found, respectively, in the present study. Similarly, Okoye et al (2009) reported higher values, for fresh fruit bunch $(45.90 \%)$ and bunch number $(57.20 \%)$. Low genetic advance values found in this study might have been due to the relatively low genetic variation because of the related ancestries of the accessions and the small number of palms per accessions. In fact, 12 palms from every progeny are to be sampled for data collection from a selfed palm to be able to capture $80 \%$ of their mother's genotype. Okwuagwu et al (2008) recommended that higher response to selection may not be obtained only from high heritability in the broad sense due to non-additive genetic variance. To obtain a higher response to selection, it is more efficient to use both heritability and genetic advance expressed as the percentage of the mean. Adhikari et al (2018) proposed a high heritability accompanied with high genetic advance expressed as a percentage of the mean for better response to selection. High heritability accompanied by moderate genetic advance was recorded for bunch weight and fresh fruit bunch which most probably implied that they were controlled by additive genes and therefore would result in a better response to selection (Kumar et al 2014; Sravanti et al 2017). 


\section{Selection of potential oil palms for crop improvement}

Dura oil palms produce a small number of large bunches as compared to pisifera oil palms that are characterized by a large number of small bunches. The hybrids i.e. tenera have intermediate performances for bunch number, which can even be higher due to the heterosis effects that prevail when the two parents are genetically distant. Fresh fruit bunch is a function of both the bunch number and the average bunch weight. Nowadays, breeding programs are more interested in dura parents of relatively high number of bunches for further improvement of this character in the tenera. The focus for oil palm breeding and selection is fresh fruit bunch (FFB) yield (Corley and Tinker 2015). Furthermore, the current breeding stocks had gone through two generations of selection. Therefore, the selection of candidate accessions was in reference to individuals possessing two or three characters desired by the industry with moderate to high heritability. These characters were the fresh fruit bunch $(\geq$ $10.81 \mathrm{t} / \mathrm{ha}$ ) representing $31-74 \%$ rise over the controls and 54-104\% above the trial mean, bunch number, average bunch weight, percent mesocarp to fruit (palm oil yieldlinked trait), and plant height equivalent to $8.9-19 \%$ rise above the controls and $8.7-16 \%$ over the trial mean. Furthermore, FFB and BN recorded moderate genetic advance values, the highest for this study. According to Bakoume and Louise (2007), good percent $\mathrm{M} / \mathrm{F}$ and oil to mesocarp (O/M) of Deli dura x La Mé (Côte d'Ivoire) progenies were transmitted by the dura parent. In addition, determination of planting density and spacing in commercial oil palm plantations should take into account plant height among other vegetative parameters (Okyere Boateng et al 2008; Murugesan and Shareef 2014). Based on the above considerations, a total of five (5) accessions were selected and proposed for introduction in the OPRI's dura improvement program (Table 3).
Table 1. ANOVA for 18 vegetative, yield and yield components, and bunch and fruit traits

\begin{tabular}{ccccc}
\hline $\begin{array}{c}\text { Agronomic } \\
\text { trait }\end{array}$ & & Replication+ & Accessions++ & Residual+++ \\
\hline LA & Mean square & 1.5531 & $0.4299^{* * *}$ & 0.0163 \\
TLA & Mean square & 1513.05 & $352.1^{*}$ & 122.89 \\
LAI & Mean square & 0.103383 & $0.04601^{* * *}$ & 0.003617 \\
FDW & Mean square & 0.11712 & $0.04926^{*}$ & 0.00897 \\
TF & Mean square & 2.58000 & $3.0862^{\text {ns }}$ & 3.35000 \\
RL & Mean square & 0.111590 & $0.16202^{* *}$ & 0.150330 \\
PH & Mean square & 290.301 & $241.346^{*}$ & 49.019 \\
Ras & Mean square & 0.16111 & $0.83404^{*}$ & 10.02801 \\
AS & Mean square & 77.147 & $49.496^{* *}$ & 6.940 \\
FFB & Mean square & 2.226 & $9.622^{* * *}$ & 0.554 \\
BN & Mean square & 1.17 & $5.644^{* *}$ & 0.993 \\
TBW & Mean Square & 74.40 & 270.30 & 21.1 \\
ABW & Mean square & 5.272 & $2.0628^{\text {ns }}$ & 3.0505 \\
SFW & Mean square & 0.661 & $1.752^{* * *}$ & 0.033 \\
F/B & Mean square & 9.81 & $18.93^{\text {ns }}$ & 21.190 \\
M/F & Mean square & 12.857 & $55.843^{*}$ & 10.691 \\
S/F & Mean square & 6.987 & $53.207^{*}$ & 21.511 \\
K/F & Mean square & 2.400 & $11.643^{\text {ns }}$ & 6.586 \\
\hline N
\end{tabular}

Note: ${ }^{+}$degrees of freedom for all trait is equal to $8,{ }^{++}$degrees of freedom for all trait is equal to $80,{ }^{+++}$degrees of freedom for all trait is equal to 88

Table 3. Agronomic performances of candidate dura accessions for introduction into OPRI's dura improvement programme

\begin{tabular}{llllcc}
\hline $\begin{array}{c}\text { Accession } \\
\text { code }\end{array}$ & $\begin{array}{c}\text { FFB } \\
(\mathbf{t} / \mathbf{h a})\end{array}$ & \multicolumn{1}{c}{$\mathbf{B N}$} & $\begin{array}{c}\text { ABW } \\
(\mathbf{k g})\end{array}$ & $\begin{array}{c}\text { M/F } \\
\mathbf{( \% )}\end{array}$ & $\begin{array}{c}\text { Height } \\
\text { increment } \\
(\mathbf{c m} / \mathbf{y r})\end{array}$ \\
\hline GHA 212/02 & 14.33 & 11.64 & 8.36 & 43.72 & 21.0 \\
GHA 209/01 & 11.74 & 8.47 & 10.09 & 44.83 & 27.0 \\
GHA 207/02 & 11.29 & 10.97 & 7.92 & 52.25 & 20.2 \\
GHA 215/02 & 11.29 & 9.46 & 10.21 & 46.38 & 24.5 \\
GHA 211/03 & 10.81 & 9.17 & 7.90 & 58.92 & 23.0 \\
Mean & 11.89 & 9.94 & 8.90 & 49.22 & 23.1 \\
Controls' mean & 8.23 & 7.50 & 7.59 & 42.49 & 22.6 \\
Trial means & 7.01 & 6.70 & 7.01 & 43.65 & 23.3 \\
\hline
\end{tabular}

Table 2. Variability of the 18 agro-morphological traits among the 79 natural dura accessions

\begin{tabular}{lllllllll}
\hline Traits & $\begin{array}{l}\text { Controls } \\
\text { mean }\end{array}$ & Min & Max & Mean & $\mathbf{h}^{2}$ & GCV (\%) & PCV $(\boldsymbol{\%})$ & GA $(\boldsymbol{\%})$ \\
\hline LA & 4.47 & 1.47 & 6.13 & 3.92 & 66.67 & 10.00 & 12.25 & 7.40 \\
TLA & 114.23 & 32.04 & 159.88 & 104.25 & 59.29 & 43.89 & 56.57 & 5.77 \\
LAI & 0.95 & 0.24 & 1.89 & 0.86 & 62.50 & 7.61 & 7.74 & 11.47 \\
FDW & 1.52 & 0.42 & 1.73 & 1.26 & 14.00 & 3.30 & 9.03 & 1.96 \\
TF & 25.87 & 23.36 & 29.96 & 26.56 & nc & nc & 35.51 & nc \\
RL & 3.29 & 2.38 & 4.06 & 3.35 & 34.78 & 4.90 & 8.24 & 2.75 \\
PH & 62.14 & 25.58 & 115.04 & 60.14 & 16.00 & 39.45 & 98.51 & 3.58 \\
Ras & 3.45 & 2.53 & 11.37 & 3.58 & 76.06 & 15.77 & 18.08 & 12.70 \\
AS & 37.21 & 19.36 & 60.26 & 39.80 & 39.70 & 33.88 & 53.77 & 5.97 \\
BN & 7.50 & 3.72 & 13.99 & 6.70 & 30.31 & 24.86 & 45.15 & 9.40 \\
TBW & 56.93 & 3.59 & 96.14 & 47.47 & 51.53 & 68.74 & 95.76 & 12.72 \\
ABW & 7.59 & 1.49 & 13.00 & 7.01 & nc & nc & 65.95 & nc \\
FFB & 8.23 & 0.41 & 14.33 & 7.01 & 46.42 & 26.08 & 38.34 & 11.78 \\
SFW & 3.64 & 3.01 & 10.21 & 5.48 & 85.27 & 18.65 & 20.25 & 2.87 \\
F/B & 48.52 & 45.78 & 67.24 & 56.18 & nc & nc & 61.42 & nc \\
M/F & 42.49 & 28.22 & 63.47 & 43.65 & 25.54 & 33.74 & 39.18 & 4.15 \\
S/F & 40.29 & 20.92 & 58.44 & 40.86 & 1.73 & 8.70 & 18.80 & 0.50 \\
K/F & 17.18 & 10.32 & 23.16 & 15.50 & 13.30 & 28.42 & 77.91 & 0.13 \\
\hline Note: & n & & & & & & &
\end{tabular}

Note: nc: not computed 
The five accessions selected represented $43 \%$ increment over the controls' mean $(8.23 \mathrm{t} / \mathrm{ha})$ and $69 \%$ over the trial mean $(7.01 \mathrm{t} / \mathrm{ha})$ mostly due to high $\mathrm{BN}$ and high $\mathrm{ABW}$. The $\mathrm{BN}$ recorded $23 \%$ increment over the controls' mean and $38 \%$ over the trial mean. The $18 \%$ and $27 \%$ increment in ABW over the controls' mean and trial mean, respectively, indicated the superiority, based on absolute values of the five accessions selected in this study. In the absence of data on oil production, emphasis was put on the $\mathrm{M} / \mathrm{F}$ a major component of oil yield. The five accessions selected for future OPRI's dura improvement program represented $13 \%$ over the controls' mean and $11 \%$ over the trial mean for M/F. In fact, Okoye et al (2009) remarked that in selecting for fruit and bunch characters in oil palm, preference should be given to mesocarp to fruit ratio when considering oil yield or palm oil production. In fact, it is not impossible for accession with high percent mesocarp to fruit to be a poor palm oil yielder but it is uncommon for an accession with low mesocarp to fruit to be best oil yielder. Low height increment of oil palms prolongs the economic life of the plantation. As palms grow higher, harvesting becomes increasingly difficult (Turner and Gillbanks 1974). In this study, though their vertical growth represented only $7 \%$ above the controls' mean and $3 \%$ over the trial mean, short progenies, are expected from parental selves or crosses given the intrinsic heterozygosity of oil palm (Bakoume and Louise 2007).

In conclusion, substantial genetic variation was found among the 79 dura oil palm accessions evaluated with respect to the 18 agro-morphological traits. Similarity of accessions was established by plant height, bunch number, average bunch weight, and percent mesocarp to fruit using the ANOVA as well as the impossibility of estimating their heritability values. The fresh fruit bunch which was usually less heritable showed to be relatively highly heritable $\left(\mathrm{h}^{2}=\right.$ 0.46) in the current study. The moderate to high genetic coefficient of variation $(\mathrm{GCV})$ indicates that some variation exists in the germplasm on which selection could capitalize for oil palm improvement. Therefore, five accessions were selected. They had a potential for improving traits of interest for the oil palm industry notably TBW, BN, ABW, $\mathrm{M} / \mathrm{F}$ and for reducing of plant height increment rate in the OPRI's dura breeding stocks.

\section{ACKNOWLEDGEMENTS}

The authors acknowledge the Oil Palm Research Institute for funding the work and Prof K. Ofori for his immense support.

\section{REFERENCES}

Adhikari BN, Prasad BJ, Shrestha J, Bhatta NR. 2018. Genetic variability, heritability, genetic advance and correlation among yield and yield components of rice (Oryza sativa L.). J Agric Nat Res 1: 149-160.

Ajayi AT, Adekola MO, Taiwo BH, Azuh VO. 2014. Character expression and differences in yield potential of ten genotypes of cowpea (Vigna unguiculata Walp). Intl J Plant Res 4: 63-71.

Ataga CD, Hamza AM, Yusuf AO. 2012. Status of date palm (Phoenix dactylifera L.) genetic resources. Intl J Life Sci Pharma Res 2: 46-51. Bakoumé C, Louise C. 2007. Breeding for oil yield and short oil palms in the second cycle of selection at La Dibamba (Cameroon). Euphytica 156: $195-202$

Bakoumé C, Ndiaye O, Okoye MN. 2017. Oil palm development in Africa. The Planter 93 (1098): 632-641.

Bakoumé C, Ngando Ebongué G, Ajambang W. 2016. Oil Palm Breeding and Seed Production in Africa. Paper presented at the International Seminar on Oil Palm Breeding and Seed Production. Kisana, Sumatra, Indonesia.

Bakoume C. (2016). Genetic diversity, erosion and conservation in oil palm. In: Genetic diversity and erosion in plants. Ahuja MR, Jain MS (eds.). Springer International Publishing, Switzerland.

Beirnaert A,Vanderweyen R. 1941. Contribution à l'étude génétique et biométrique des variétiés d' Elaeis guineensis Jacq. Publ Inst Nat Etude Agron Congo Belge Ser Sci 27 1-101. [France]

Bhandari HR, Bhanu AN, Srivastava K, Singh MN, Shreya, Hemantaranjan A. 2017. Assessment of genetic diversity in crop plants-an overview. Adv Plants Agric Res 7: 279-286.

Constantin MC, Sobir S, Syukur M, Suwarno AWB. 2017. Performance, heritability, genetic advance for oil yield and some economic characters in oil palm (Elaeis guineensis Jacq) of Cameroon. J. Agron Indonesia 45: 212-219.

Corley RHV and Tinker PBH. 2015. The Oil Palm. $5^{\text {th }}$ ed. Blackwell Science Ltd, Oxford, UK.

Farshadfar E, Estehghari MR. 2014. Evaluation of phenotypic variability, genetic parameters, heritability and genetic gain in bread wheat genotypes under rainfed conditions. Intl J Biol 4: 193-201.

Kumar GP, Narsimha RV, Sudheer SK. 2014. Genetic variability, heritability, genetic advance studies in newly developed maize genotypes (Zea mays L.). Intl J Pure Appl Sci 1: 272-275.

Li-Hammeda MA, Kushairi, AD, Rajanaidu N. 2016. Genetic variability for yield, yield components and fatty acid traits in oil palm (Elaeis guineensis Jacq.) germplasm using multivariate tools. Intl J Agric For Plant 2: 219-226.

Murugesan P, Rani KLM, Ramajayam D, Kumar RK, Mathur RK, Ravichandran G, Kumar PN, Arunachalam V. 2015. Genetic diversity of vegetative and bunch traits of African oil palm (Elaeis guineensis Jacq) germplasm in India. Ind J Agric Sci 7: 892-895.

Murugesan P and Shareef M. 2014. Yield, bunch quality and vegetative traits of American oil palm (Elaeis oleifera, HBK) population in India. Indian J Hort 71: 23-27

Okoye MN, Okwuagwu CO, Uguru MI. 2009. Performance of 5 Deli dura parents in the NIFOR oil palm breeding programme. Acad J Plant Sci 2: $139-49$

Okoye MN, Uguru MI, Bakoume C, Rajinder S, Okwuagwu CO. (2016) Assessment of genetic diversity of NIFOR oil palm breeding parent genotypes using microsatellite markers. Am J Plant Sci 7: 218-237

Okyere-Boateng G, Dwarko DA, Kaledzi PD. 2008. Collection, conservation and evaluation of the disappearing oil palm (Elaeis guineensis) landraces in Ghana. Intl J Pure Appl Sci 3: 18-24.

Okwuagwu CO, Okoye MN, Okolo EC, Ataga CD. 2008. Genetic variability of fresh fruit bunch yield in Deli /dura x Tenera breeding populations of oil palm (Elaeis guineensis Jacq.) in Nigeria. J Trop Agric 46: 52-57.

Pratap N, Singh PK, Shekhar R, Soni SK, Mall AK. 2012. Genetic variability, character association and diversity analyses for economic traits in rice Oryza sativa L.). SAARC J Agric 10 (2): 83-94

$\mathrm{R}$ Core Team. 2018. A language and environment for statistical computing. R Foundation for Statistical Computing, Vienna, Austria. https://www.R-project.org.

Sapey E, Adusei-Fosu K, Darkwah DO, Agyei-Dwarko D. 2017. Multivariate analysis of bunch yield and vegetative traits of oil palm germplasm conserved at Oil Palm Research Institute (OPRI)-Ghana. Intl J Plant Breed Crop Sci 4:231-236.

Sayan S, Sudanai K, Theera E, Vinich S. 2013. Correlation and path analysis of oil palm yield components in oil palm (Elaeis guineensis Jacq). Kasetsart J Nat Sci 47: 528-533.

Sravanti K, Swarnalatha I, Sudarshan MR, Supriya K. 2017. Evaluation of maize genotypes for variability, heritability, and genetic advance. Intl J Microb App Sci 6 (10): 2227-2232.

Turner PD, Gillbanks RA. 1974. Oil palm cultivation and management, 1 st ed. The Incorporated Society of Planter, Kuala Lumpur.

Wonkyi-Appiah JB. 1987. Genetic control of fertility in the oil palm (Elaeis guineensis Jacq). Euphytica 36: 505-511. 